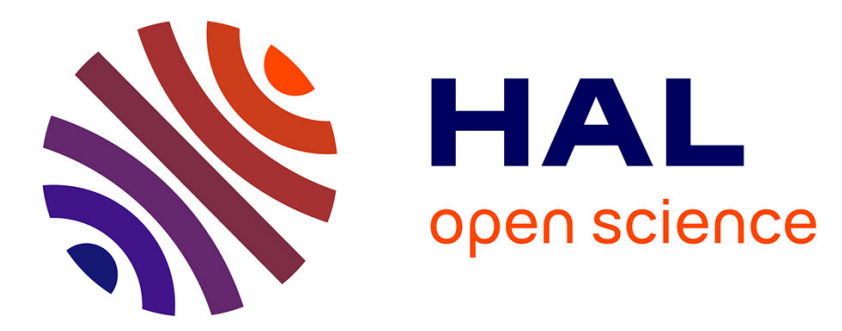

\title{
Comparative observations on the premolar root and pulp canal configurations of Middle Pleistocene Homo in China
}

\author{
Lei Pan, Clément Zanolli
}

\section{> To cite this version:}

Lei Pan, Clément Zanolli. Comparative observations on the premolar root and pulp canal configurations of Middle Pleistocene Homo in China. American Journal of Physical Anthropology, 2019, 168 (3), pp.637-646. 10.1002/ajpa.23777 . hal-02296702

\section{HAL Id: hal-02296702 \\ https://hal.science/hal-02296702}

Submitted on 25 Feb 2021

HAL is a multi-disciplinary open access archive for the deposit and dissemination of scientific research documents, whether they are published or not. The documents may come from teaching and research institutions in France or abroad, or from public or private research centers.
L'archive ouverte pluridisciplinaire HAL, est destinée au dépôt et à la diffusion de documents scientifiques de niveau recherche, publiés ou non, émanant des établissements d'enseignement et de recherche français ou étrangers, des laboratoires publics ou privés. 


\title{
Comparative observations on the premolar root and pulp canal configurations of Middle Pleistocene Homo in China
}

Lei Pan ${ }^{1,2}$, Clément Zanollii ${ }^{3,4}$

1 Key Laboratory of Vertebrate Evolution and Human Origins, Institute of Vertebrate Paleontology and Paleoanthropology, CAS, Beijing, China

2 State Key Laboratory of Palaeobiology and Stratigraphy, Nanjing Institute of Geology and Palaeontology, CAS, Nanjing, China

3 Laboratory AMIS, UMR 5288 CNRS, Université Toulouse III - Paul Sabatier, France 4 Laboratory AMIS, UMR 5288 CNRS, Université Toulouse III - Paul Sabatier, France

\begin{abstract}
Objectives: The aim of this study is to explore the root and root canal morphology of Homo fossil occupying China during the Middle Pleistocene period. Human occupation and evolutionary dynamics in East Asia during the Middle Pleistocene period is one of the most intriguing issues in paleoanthropology, with the coexistence of multiple lineages and regional morphs suggesting a complex population interaction scenario. Although premolar root and canal morphology has certain phylogenetic, taxonomic, and functional implications, its morphological diversity, possible evolutionary trend and characteristics regarding Middle Pleistocene hominins inhabiting East Asia are still insufficiently understood; where these populations fits within the Homo lineage (with respect to root and pulp canal structure) needs to be explored. Materials and methods: Using microtomography, we directly observed and assessed the nonmetric variability of root and canal forms in maxillary and mandibular premolars of Chinese Middle Pleistocene Homo $(\mathrm{N}=19)$, and compared our observed variations with Eurasian Early Pleistocene specimens from the Asia continent $(\mathrm{N}=1)$ and Java $(\mathrm{N}=2)$, as well as with Neanderthals $(\mathrm{N}=28)$ and recent
\end{abstract}


modern humans $(\mathrm{N}=67)$. Results: A total number of nine types of root-canal forms were recorded. As a whole, the Chinese Middle Pleistocene record shows an evolutionary trend toward a modern human-like condition (a reduction of root/canal number and a simplification of root surface structure). We documented primitive signals like high percentage of Tomes' root in lower premolars. A considerable occurrence of incompletely separated root branches and bifid root and canal apices, representing evolutionary transformation from multi-root to single-root condition was also noticed. The results were compared with previous publications on Early and Middle Pleistocene Homo in East Africa, North Africa, and Eurasia. Conclusion: This work provides new original data, incorporates the latest human fossil discoveries and suggests that analyzing the variation of premolar root structural organization, notably integrating together root/canal form and number, could possibly contribute to taxonomic and phylogenetic assessments. The mid-Middle Pleistocene populations, or "classic" Homo erectus, in our study show closer affinity to Early and Middle Pleistocene hominins in Eurasia, than to East African early Homo, which supports the suggestion that at least some of the Early Pleistocene hominin groups in Eurasia contribute to the later population; on the other hand, it is still difficult to clearly trace the evolutionary fate of those late Middle Pleistocene populations (roughly assigned as archaic Homo sapiens through a craniodental perspective). More comparable materials from the Early to Middle Pleistocene period as well as precise chronological framework is needed to further explore the evolutionary trends of archaic hominins in the Asian continent before the arrival of modern humans.

\section{Introduction}

Recent discoveries revealed different evolutionary lineages and a considerable degree of isolation among regional populations in Middle Pleistocene Asia (rev. in Kaifu, 2017). Marked differences were reported for the internal tooth crown morphology of Chinese and Indonesian Middle Pleistocene humans, possibly suggesting that distinct groups may have 
populated continental and (pen)insular Asia (Liu et al., 2017; Liu, Clarke, \& Xing, 2010; Liu, Xing, \& Wu, 2016; Xing, 2012; Xing et al., 2016). In particular, complex occlusal crown surface and enamel-dentine junction morphology (represented by additive traits like interconnected ridges, bifurcated essential crests, and accessory ridges and cusps) is found in the Chinese dental assemblages across the Middle Pleistocene, including the earliest specimens from Zhoukoudian (Xing, Martinón-Torres, \& Bermúdez de Castro, 2018), the mid-Middle Pleistocene teeth from Chaoxian, Hexian, and Yiyuan (Bailey \& Liu, 2010; Liu et al., 2017; Xing et al., 2014, 2016), and the late Middle to early Late Pleistocene material from Panxian Dadong and Xujiayao (Liu et al., 2013, 2016; Xing et al., 2015). These findings revealed characteristic patterns for the populations that inhabited East Asia during the Middle Pleistocene period, like highly crenulated enamel-dentine junction (EDJ) and its imprint on the roof of the pulp cavity (Xing et al., 2016, 2018), and highlighted a combination of primitive and derived features that cannot be organized along a temporal scale (Liu et al., 2017). Based on dental evidence, those early- and mid-Middle Pleistocene specimens are aligned to the "classic" Homo erectus hypodigm and it is proposed that Early Pleistocene hominins in Eurasia contributed to at least some of the later H. erectus lineages, and that these populations experienced relatively independent evolutionary courses compared with $H$. erectus in the African continent (Kaifu, 2017; Kaifu et al., 2005; Martinón-Torres et al., 2007, 2008). On the other hand, craniodental evidence is still insufficient to resolve the taxonomic and phylogenetic identity of late Middle Pleistocene hominins and how they relate to modern Homo sapiens. Except for a retention of primitive traits, like large and robust roots, and a trend toward root number reduction (Liu et al., 2013, 2017; Xing et al., 2014, 2018), the morphological diversity and phylogenetic implications of the root-canal structure of these hominin populations are still unclear; comparative study is needed to fully reveal the root and canal structure for the Chinese materials from this period. The variability of form, number and position of fossil hominin and extant human premolar roots and/or pulp canals has been described in previous 
research as reflecting functional/biomechanical demand, developmental aspects, sexual dimorphism, and taxonomy (Abbott, 1984; Kottoor, Albuquerque, Velmurugan, \& Kuruvilla, 2013; Kupczik \& Dean, 2008; Kupczik, Spoor, Pommert, \& Dean, 2005; Moore, Hublin, \& Skinner, 2015; Moore, Skinner, \& Hublin, 2013; Moore, Thackeray, Hublin, \& Skinner, 2016; Spencer, 2003; Wood \& Engleman, 1988). Root morphology and pulp canal form, number, and size are the result of variations in the development of Hertwig's epithelial root sheath that determines the location, number and expression of inter-radicular processes (Kovacs, 1967, 1971; Shields, 2005; Moore et al., 2013). Hominid root complexity (single vs. multiple roots) and length are generally interpreted to play a role in the dispersion of occlusal loading during mastication and paramasticatory activities, but root number alone does not reflect a functional adaptation related to area of root attachment (Kupczik et al., 2005). Root and canal configurations are also associated with complex genetic, and epigenetic mechanisms as well as environmental influences (Brook, 2009; Shields, 2005; Tobias, 1995). But tooth root structural organization also holds critical taxonomic information and represents a phylogenetic indicator for distinguishing closely related extinct hominid species (Moore et al., 2013, 2016). Within the Pan-modern human lineage, while variations exist, the plesiomorphic great-ape pattern is represented by (a) three-rooted maxillary premolars with three canals, arranged as two buccal and one lingual root, and (b) double-rooted mandibular premolars with three $\left(\mathrm{P}_{3}\right)$ or four $\left(\mathrm{P}_{4}\right)$ canals (Abbott, 1984). In contrast, modern humans show a series of apomorphic condition: modern human upper premolars are usually single-rooted (Abbott, 1984; Peiris, 2008; Wood \& Engleman, 1988), but in certain populations, predominant doublerooted P3s have been recorded (Shaw, 1931), and sub-Saharan populations even show a wider range of variability (Shields, 2005). Regarding lower premolars, the modern human condition is a single root, although variations such as Tomes' root have been reported (see Loh, 1998; Peiris, 2008; Sert \& Bayirli, 2004; Shields, 2005; Tomes, 1923). Among fossil taxa, elaborated or "molariform" lower premolar roots (each plate-like and contains two canals) 
are seen in Australopithecus and Paranthropus (Moggi-Cecchi, Menter, Boccone, \& Keyser, 2010; Moore et al., 2016; White, Suwa, Simpson, \& Asfaw, 2000; Wood, Abbott, \& Uytterschaut, 1988). Regarding Homo, an apomorphic condition with respect to australopiths and a trend towards the reduction in root radicule and pulp canal number is expressed. Although doublerooted premolars exist, the East African Homo exhibits predominantly single or Tomes' root conditions, whereas primitive double-rooted lower premolars can be observed in some other members of Early Pleistocene H. erectus s.l. from Dmanisi (D2600) and Sangiran (Sangiran 5, 8, and 9; Kaifu et al., 2005; Martinón-Torres et al., 2008), as well as in H. antecessor and H. naledi (Berger et al., 2015; Bermúdez de Castro, Martinón-Torres, Sier, \& Martín-Francés, 2014; Bermúdez de Castro \& Rosas, 1999). In addition, the mandibular premolars of $H$. naledi are somewhat molarized (Berger et al., 2015).

\subsection{Goals of this study}

To date, root and pulp canal structure has been reported for a number of archaic Homo in East Asia (Chang et al., 2015; Liu et al., 2013, 2017; Xing et al., 2014, 2018; Zanolli et al., 2018); previous investigations (Liu et al., 2013; Xing et al., 2018) have revealed a general trend toward root number reduction, but a retention of primitive traits is still represented in particular cases like Hexian H. erectus (Liu et al., 2017; Xing et al., 2014) and Penghu 1 mandible (Chang et al., 2015). However, the root and pulp canal structure of Chinese Middle Pleistocene hominins has not been sufficiently recorded (especially late Middle Pleistocene specimens that are generally assigned to archaic $H$. sapiens). Moreover, comparative investigations focusing on the root and canal morphology are needed, to better understand where these populations fit along the Homo lineage. We incorporated the latest discoveries and characterized here the extent of root number and pulp canal variation in an extensive sample of Chinese Middle Pleistocene premolars. More specifically, we used micro-CT scans of the majority of the Chinese Middle Pleistocene Homo specimens 
suitable for rootcanal investigation to document and assess the variability of premolar rootcanal system. We compared results on this Chinese fossil sample with Early Pleistocene Homo from the Asian continent and Java, as well as with Late Pleistocene Neanderthals and recent modern humans.

\section{Materials and method}

\subsection{Study sample}

The samples comprise a total of 117 permanent maxillary and mandibular premolars from fossil and extant individuals from a variety of chronological and geographical origins. The Chinese Middle Pleistocene Homo sample (CMPH) includes 19 teeth, with a chronological age ranging from mid-Middle to late-Middle Pleistocene, scattering amongst 8 archaeological localities. It should be noted that the specimens from Xichuan lack accurate stratigraphic context, but their morphological signature could be compared to Zhoukoudian $H$. erectus and therefore it is acknowledged that Xichuan hominins are H. erectus $(\mathrm{Wu}$, $\mathrm{Wu}$, 1982). We compared the results of Chinese Middle Pleistocene Homo with Neanderthals (NEA, N=28), recent modern humans (RMH, N=67) and two Early Pleistocene $H$. erectus individuals from East Asian continent and Indonesia. Our modern human reference material comes from clinical extractions and anatomical collections, sampling Asian, European and South African individuals; our Neanderthal sample comes from Krapina site, in Croatia, and La Chaise, France (NESPOS database, 2017) (SOM Table 1). We selected specimens with well-preserved roots, when antimeres exist, the better-preserved side is chosen; when both antimeres are well preserved, the left side is chosen (regarding our sample, well-preserved antimeres exhibit the same root pattern).

Except for PMU M 3887 housed at Uppsala University (which was scanned using X-ray microtomography $(\mu \mathrm{CT})$ at the Multidisciplinary Laboratory of the ICTP, Trieste (Tuniz et al., 2013; Zanolli et al., 2018a), all other Chinese specimens (fossil and recent humans) were scanned using a $225 \mathrm{kV}-\mu \mathrm{XCT}$ scanner at the Institute of Vertebrate Paleontology 
and Paleoanthropology (IVPP, Chinese Academy of Sciences); micro-CT data or STL mesh of the Neanderthals were downloaded from the NESPOS Database (NESPOS database, 2017); data for South African modern human specimens were produced on an XTek (Metris) XT H225L industrial XCT system at the South African Nuclear Energy Corporation (Necsa) (Hoffman, de Beer, 2012); European modern human specimens were acquired using a Phoenix Nanotom 180 scanner from the FERMAT Federation from the Inter-university Material Research and Engineering Centre (CIRIMAT, UMR 5085 CNRS). Isometric voxel size ranged from 40 to $70 \mu \mathrm{m}$. Each specimen was segmented in Avizo 8.0 (Visualization Sciences Group, www.vsg3d.com). After the segmentation, the root and canal system was generated using the "unconstrained smoothing" parameter.

Table 1. Composition of the study sample.

\begin{tabular}{l} 
Specimen \\
\hline Chinese Middle
\end{tabular}

\section{Pleistocene Homo}

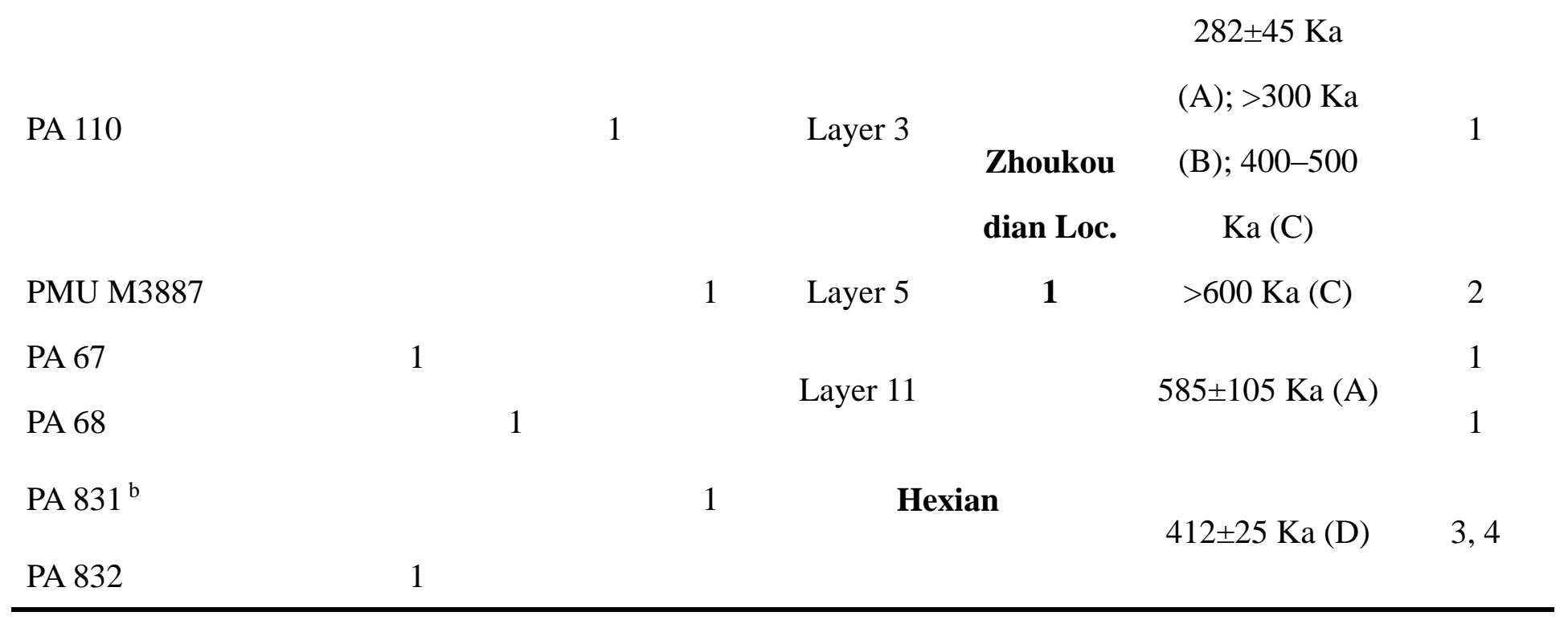




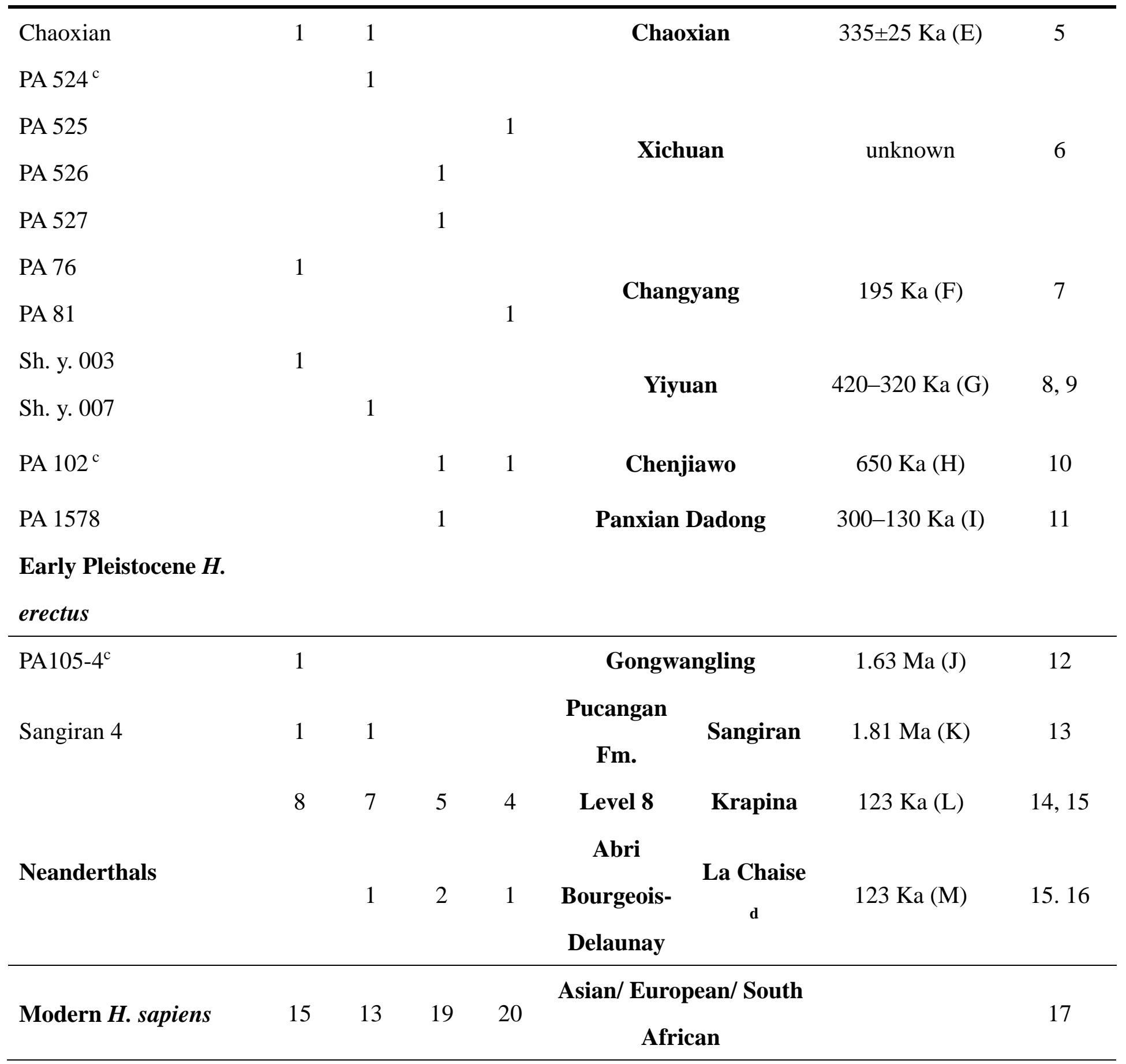

a) Age : (A) Huang et al. (1993) ; (B) Grün et al. (1997) ; (C) Shen et al. (2001) ; (D) Grün et al. (1998) ; (E) Shen et al. (2010); (F) Yuan et al. (1986) ; (G) Han et al. (2016) ; (H) An and Kun (1989); (I) Schepartz and Miller-Antonio (2004); (J) Zhu et al. (2015); (K) Huffman (2001) ; (L) Rink et al. (1995) ; (M) Macchiarelli et al. (2006) 
b) Citations: (1) Xing (2012); (2) Zdansky (1952); (3) Xing et al. (2014); (4) Liu et al. (2017); (5) Bailey and Liu (2010) (6) Wu and Wu (1982); (7) Chia (1957); (8) Lü et al. (1989); (9) Xing et al. (2016); (10) Woo (1964); (11) Liu et al. (2013); (12) Woo (1966); (13) von Koenigswald and Weidenreich (1939); (14); (15) NESPOS database (2017); (16) Macchiarelli et al. (2006) ; (17) Pan et al. (2017)

c) Strongly worn crowns

d) Damaged apex, but indications of two root branches

\subsection{Root and canal classification}

Abbott (1984) and Wood et al. (1988) established categories to classify external root number and form: the first number refers to the number of roots, followed by letter(s) that indicate root form/configuration. Under such criteria, mandibular premolar roots could be characterized into four forms (Wood et al., 1988): 1R, 2T, 2R MB + D (mesiobuccal and distal) and 2R M + D (mesial and distal). 1R was defined as a single root with a single (main) canal (single-rooted Tomes' root with one apex is included in this category); 2T was defined as the Tomes' root or C-shaped root with bifid apex (Tomes, 1923), where each root has a separate pulp canal. This classification system was later extended by Moore et al. $(2013,2015,2016)$ to combine both the external root traits and internal canal parameters. The classification typology we used here was adapted from formula set by Moore et al. (2013, 2015, 2016), slight modifications were made in order to highlight number of roots. The formula and description of each root/canal type is listed in Table 2. Multi-rooted premolars were defined on the basis of furcation exceeding more than $25 \%$ of the total root length, from cervix to root apex, and the classification of Tomes' root was done following ASUDAS (Turner, Nichol, \& Scott, 1991). The evaluation of root and canal types were performed three times by the same observer (LP).

Table 2. List of premolar root and canal formulae identified in our sample 


\begin{tabular}{|c|c|c|c|}
\hline Formula & $\begin{array}{l}\text { Root } \\
\text { number }\end{array}$ & $\begin{array}{l}\text { Canal } \\
\text { number }\end{array}$ & Description \\
\hline $1 \mathrm{R}_{1}$ & 1 & 1 & No bifurcation; 1 root/1 canal \\
\hline $1 \mathrm{R}(\mathrm{Bf})_{1 \mathrm{Bf}}$ & 1 & 1 & $1 \mathrm{bifid}$ root/1 bifid canal \\
\hline $1 \mathrm{R}_{1 \mathrm{Bf}}$ & 1 & 1 & 1 single root/1 bifid canal \\
\hline $1 \mathrm{R}_{2(1 \mathrm{~B}+1 \mathrm{~L})}$ & 1 & 2 & $1 \operatorname{root}($ joined $1 \mathrm{~B}+1 \mathrm{~L}$ roots $) / 2$ circular canals $(1 \mathrm{~B}+1 \mathrm{~L})$ \\
\hline $1 \mathrm{~T}_{1}$ & 1 & 1 & $\begin{array}{l}\text { Tomes’ root; } 1 \text { C-shaped root body (deep ML } \\
\text { groove, round DB face)/1 C-shaped canal }\end{array}$ \\
\hline $1 \mathrm{~T}_{2(1 \mathrm{~B}+1 \mathrm{~L})}$ & 1 & 2 & $\begin{array}{l}\text { Tomes' root; } 1 \text { C-shaped root body/2 circular canals } \\
(1 \mathrm{~B}+1 \mathrm{~L})\end{array}$ \\
\hline $1 \mathrm{~T} 2(1 \mathrm{MB}+1 \mathrm{DL})$ & 1 & 2 & $\begin{array}{l}\text { Tomes' root; } 1 \text { C-shaped root body } / 2 \text { circular canals } \\
(1 \mathrm{MB}+1 \mathrm{DL})\end{array}$ \\
\hline $2 \mathrm{R}: 1{ }_{1} \mathrm{~B}+1_{1} \mathrm{~L}$ & 2 & 2 & $\begin{array}{l}2 \text { roots }(1 \mathrm{~B}+1 \mathrm{~L} \text { circular }) / 2 \text { circular canals }(1 \mathrm{~B}+1 \mathrm{~L}) \text {. } \\
\text { Double roots but incompletely separated, fully-grown } \\
\text { root branches are included }\end{array}$ \\
\hline $3 \mathrm{R}: 2{ }_{2} \mathrm{~B}+1{ }_{1} \mathrm{~L}$ & 3 & 3 & 3 roots $(2 \mathrm{~B}+1 \mathrm{~L}) / 3$ circular canals $(2 \mathrm{~B}+1 \mathrm{~L})$ \\
\hline
\end{tabular}

\section{Results}

Among the examined groups, we identified a total of nine types of root and pulp canal configurations (Table 2). Upper premolars show single, double or triple roots with one, two or three canals; lower premolars are single- or Tomes'- rooted and have one or two canals. The Figures 1 and 2 show the percentage of root-canal type in each group with reference to dental position, as well as a representative cross-sectional image of each root-canal type, while the Figure 3 shows the percentage of premolar root/canal type in the three groups investigated in the present study. Root type of each fossil specimen was listed in Supplementary Online Material (SOM) Table 1. 


\subsection{Variation of root and canal types among dental position and groups}

Maxillary premolars

Two-thirds of Chinese fossil $\mathrm{P}^{3}$ s shows double roots with two canals (Figs. 1 and 3), one specimen (PA 832) has triple roots with two buccal and one lingual canals (SOM Table 1). The root configuration of this specimen has been previously reported (Xing et al., 2014). Zhoukoudian specimen PA 67 shows incompletely separated B+L roots, connected by cementum; $\mathrm{P}^{3}$ specimens sh.y.003 as well as Chaoxian have two independent, $\mathrm{B}+\mathrm{L}$ roots, and PA 76 has single root with B+L canals (SOM Table 1). The Early Pleistocene $H$. erectus representatives Sangiran 4 and PA 105-4 also show two separate roots with a pulp canal in each branch (SOM Table 1), because of a small sample size, these early specimens were not introduced in the frequency counts or in Figures 1,2 and 3, but micro-CT sections are presented in SOM. The frequency of double-rooted $\mathrm{P}^{3} \mathrm{~s}$ is also high in recent modern humans and Neanderthals (68.8\% and 100\%, respectively) (Figs. 1 and 3). Modern human $\mathrm{P}^{3} \mathrm{~s}$ present two cases of single joined root with two canals, and one specimen has apical bifurcation (Fig. 1).

$\mathrm{P}^{4} \mathrm{~s}$ vary in root number between one and two. One half of Chinese Middle Pleistocene sample show double roots and two canals (Fig. 1). Specimen PA 68 has a bifid root apex with a bifid canal (SOM Table 1); sh.y.007 has single, plate-like root with two canals; double roots and two B+L canals form is expressed for PA 524 (SOM Table 1), the buccal and lingual components are separated by a deep groove at the mesial side (n.b., this root is damaged, but a sign of two branches can be seen). The $\mathrm{P}^{4}$ of the Javanese specimen Sangiran 4 shows a deep furrow at the distal face of the root with two pulp canals almost linked together by thin buccolingual elongations, similar as the configuration of Chaoxian UP4 (SOM Table 1). Double-rooted $\mathrm{P}^{4} \mathrm{~S}$ is observed in modern humans (38.5\%), and more frequently, in Neanderthals (87.5\%) (Figs 1 and 3). 
Figure 1. The frequency of root-canal types in upper premolar. Examples of each root type in cross-section image are shown.

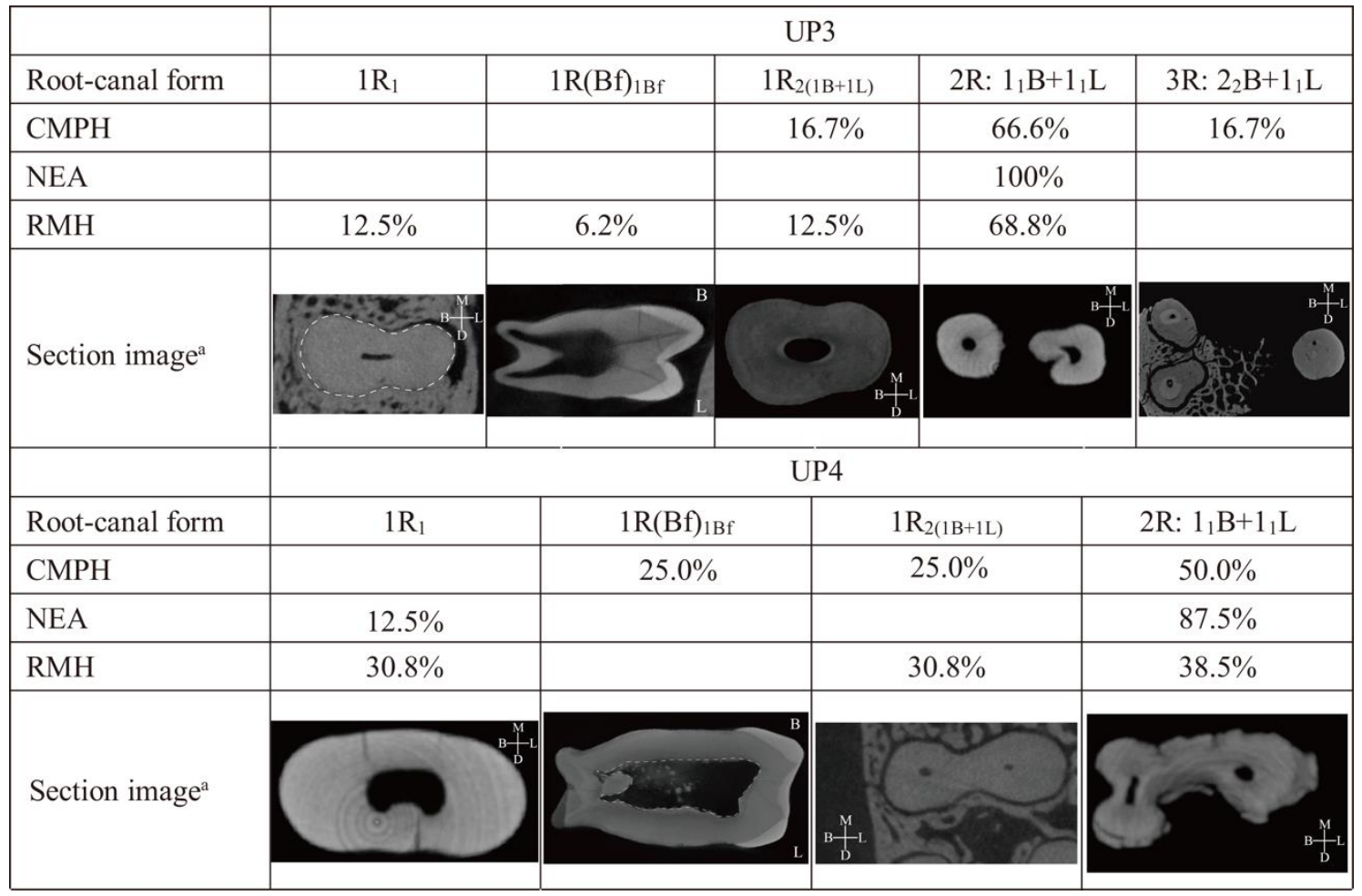

a): For 1R1 premolars, cross-sectional images were captured at mid-root; for multi-rooted and/or multicanaled premolars, cross-sectional images were captured at the furcation location; for bifurcated premolars, buccal-lingual sections were taken to show the furcation more clearly. All right-sided images were flipped to the left side.

\section{Mandibular premolars}

Across the sample, root type varies between single circular, bifid, and Tomes' root, canal number varies between one and two (Figs. 2 and 3). A key difference between Chinese Mid-Pleistocene fossil and the other two groups is the relatively high prevalence of Tomes' root (Figs. 2 and 3). In $\mathrm{P}_{3}$ s, a two-canaled Tomes' type with C-shaped buccal face and deep MB-DL groove is expressed for Chinese fossils (60\%), followed by single circular root with one canal (40\%); in $\mathrm{P}_{4 \mathrm{~s}}, 2$ fossil specimens were discovered with Tomes' root (50\%). The two-canal, Tomes' rooted $\mathrm{P}_{4}$ is reported in single case (PA 831), at the external surface of the root (SOM Table 1), a mesiobuccal and a distolingual radical grooves are separated by a deep lingual invagination (Liu et al., 2017). Note that only the apical third of this $\mathrm{P}_{4}$ 
is preserved, embedded in the mandibular corpus. Three moderate radicular grooves $(\mathrm{M}$, D and L) are seen at the root surface of PA 81, together with a crescent-shaped canal in cross-section, these characteristics thusly differentiate this root from a typical single-rooted premolar, and categorize itself as a non-typical Tomes' root (SOM Table 1). In modern human lower premolars, the prevalence of Tomes' root is $27.8 \%$ for $\mathrm{P}_{3}$ and $15 \%$ for $\mathrm{P}_{4}$ (Figs. 2 and 3). It is also interesting to note that compared with the other two groups, Neanderthals $\mathrm{P}_{3}$ s show a relatively high percentage of single root with bifurcation at the root and canal apex (37.5\%) (Figs. 2 and 3).

Figure 2. The frequency of root-canal types in upper premolar. Examples of each root type in cross-section image are shown.

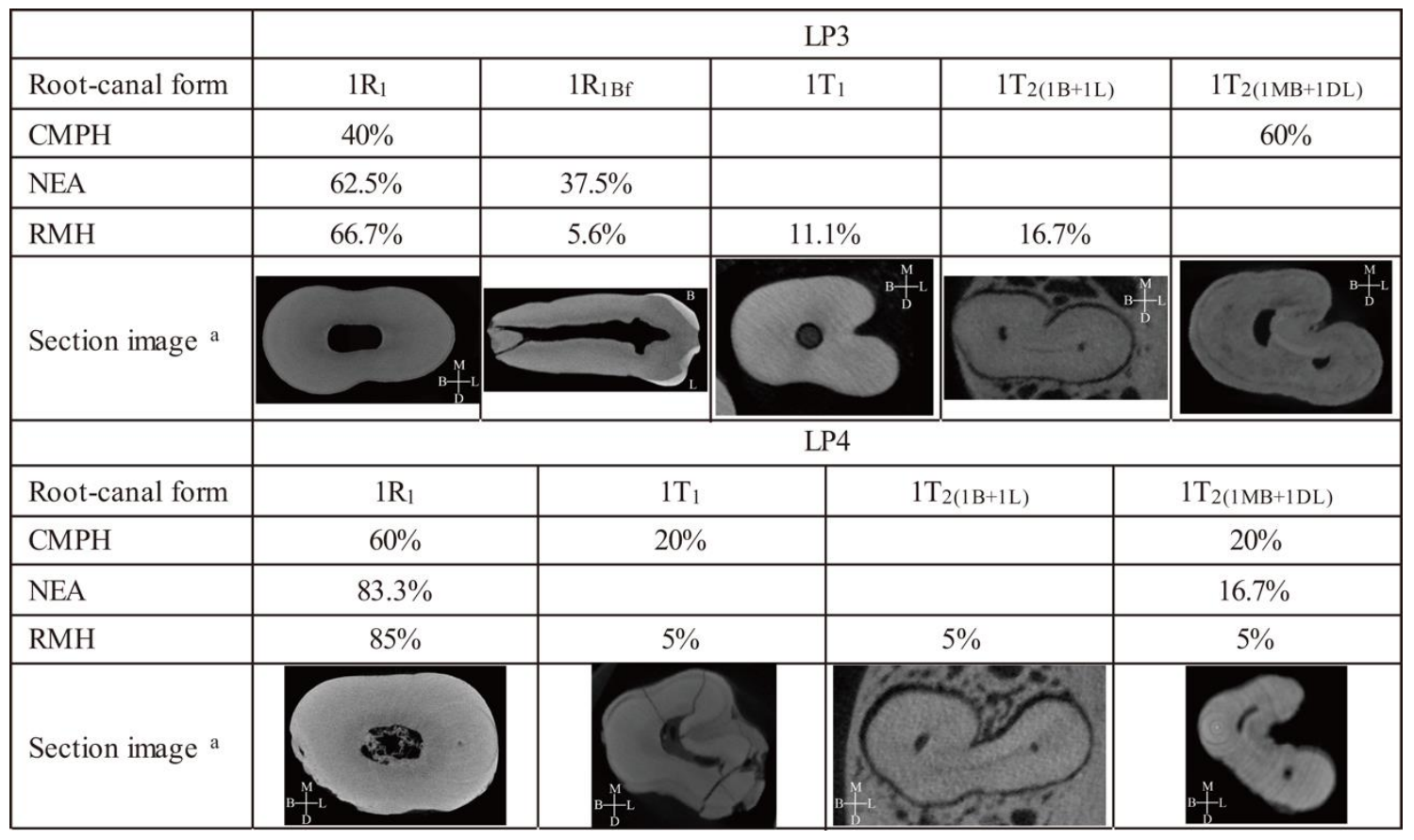

a): For 1R1 and 1T1 premolars, cross-sectional images were captured at mid-root; for multi-rooted and/or multi-canaled premolars, cross-sectional images were captured at the furcation location; for bifurcated premolars, buccal-lingual sections were taken to show the furcation more clearly. All right-sided images were flipped to the left side.

\subsection{Additional morphological traits and variants within root/canal formula}


As noticed by Moore et al. (2015, 2016), double-rooted upper premolars (referred as formula $11 \mathrm{~B}+11 \mathrm{~L}$ or root type $2-\mathrm{A}-2$ by Moore and colleagues) have a number of variants within hominoids, and this is in accordance with our observations. In $\mathrm{P}^{3}$ of Zhoukoudian H. erectus, two root branches are presented but not completely separated: cementum tissue connects root branches at the mesial face, and a deep and wide furrow is seen at the distal face, located at the middle third and extending to the apex of the root, with two, clearly separated $\mathrm{B}+\mathrm{L}$ canals. This root configuration is also seen in the $\mathrm{P} 4 \mathrm{~s}$ of Javanese $H$. erectus Sangiran 4, Chaoxian P4, and also in some of the Neanderthal P4s (Supporting Information Table 1), but is absent in early $H$. erectus specimen PA $105-4$, not frequently observed in our modern humans.

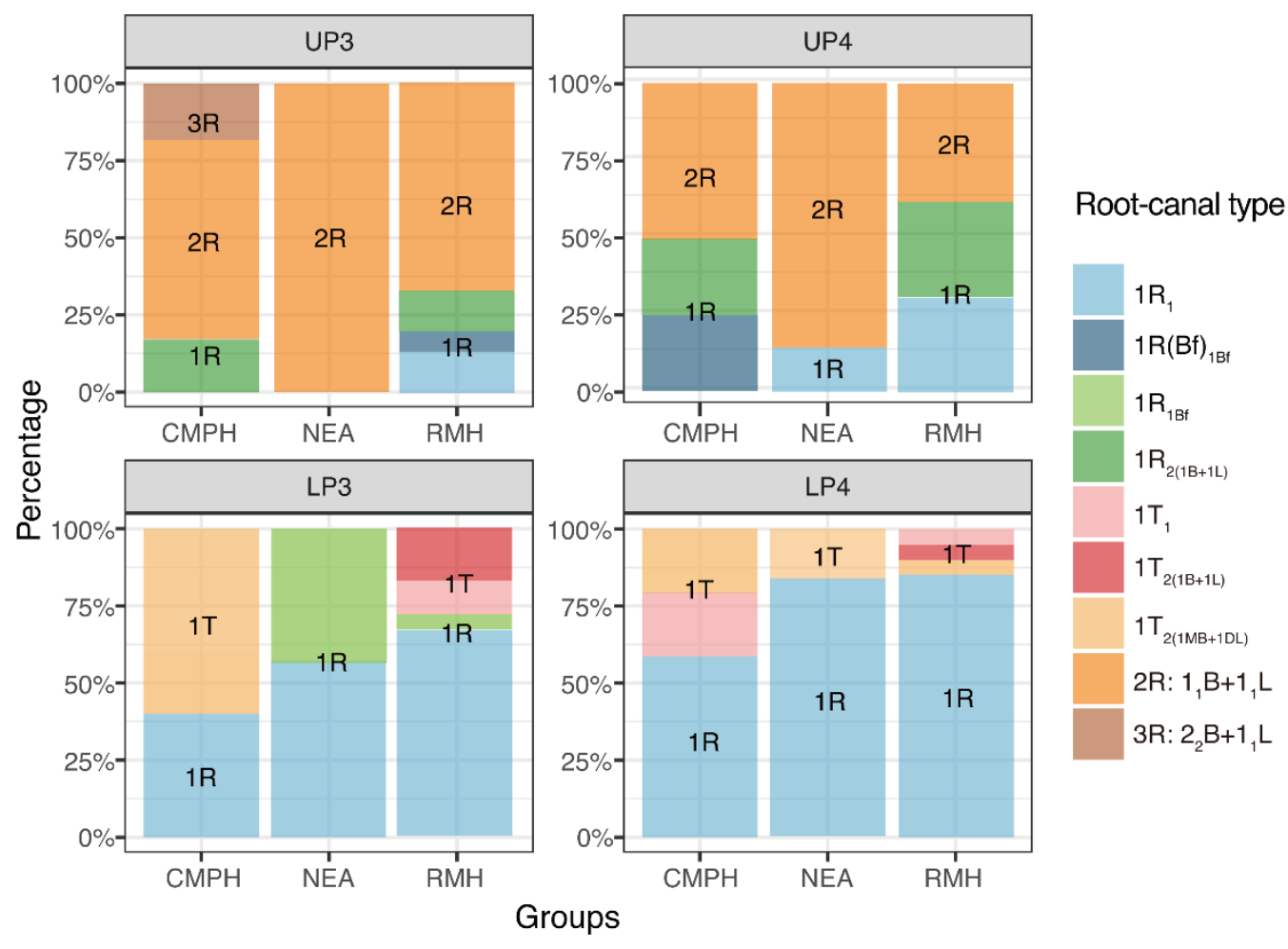

Figure 3. Root and canal type in Chinese Middle Pleistocene Homo (CMPH), Neanderthals (NEA) and recent modern humans (MH).

\section{Discussion}




\subsection{Inter-group comparisons of root and canal form}

Recent studies on the dentition of Chinese hominin fossils from Middle Pleistocene period (including a number of fossils involved in this study) have reported a combination of derived and primitive traits expressed at premolar roots and/or root canals. Compared with early members of $H$. erectus s.l. (e.g., specimens from Dmanisi, East Africa, and Sangiran), upper premolars from Zhoukoudian and Yiyuan have less complex root and canal structures, whereas the lower premolars are closer to the early Homo condition (MartinónTorres et al., 2008; Xing et al., 2018; Zanolli, Pan, et al., 2018). On the other hand, Hexian $H$. erectus differs from northern Chinese $H$. erectus and European Middle Pleistocene hominins by showing primitive affinities (three-rooted upper premolar, robust mandible and premolar roots) with the Early Pleistocene specimens from Africa (H. ergaster) and Java (H. erectus; Liu et al., 2017; Xing et al., 2014). Another study states that $\mathrm{P}_{3}$ from Panxian Dadong shows a slightly robust root compared with modern H. sapiens, but the archaic features are very weakly expressed (Liu et al., 2013); our observation on the root and canal form confirms that this late Middle Pleistocene hominin specimen has a simple root system (single root with one canal), a condition that is commonly found in recent humans. Besides these above-mentioned, previous records, the root and canal system of Middle Pleistocene hominins from China is still insufficiently documented: little is known about their morphological variability, leaving inconclusive discussions about their taxonomical and phylogenetic places in relation to contemporary hominins from Africa and Eurasia. We extend the knowledge on fossil human tooth variability by providing the first detailed document of the root-pulp canal system variation of Asian hominins living in this particular time period. The primitive hominin root morphology, as represented by the maxillary premolars of South African australopiths, are double- or triple-rooted (Moore et al., 2016). Triple-rooted $\mathrm{P}^{3} \mathrm{~s}$ are also observed in Early Pleistocene Homo from Sangiran (older deposits; Kaifu et al., 2005; von Koenigswald, 1950). Contrasting this "molarized" primitive condition, our representatives of Asian Early Pleistocene Homo (Sangiran 4 and PA 105-4), as well as Chinese Middle Pleistocene sample, show a clear trend of root reduction (toward modern human condition). Chinese specimens in general exhibit a derived condition of predominantly double-rooted $\mathrm{P}^{3} \mathrm{~s}$ and single-rooted $\mathrm{P}^{4} \mathrm{~s}$ (see also Xing et al., 2018), close to the frequency seen in modern humans (Figure 1), although variations like triple- and single-rooted $\mathrm{P}^{3} \mathrm{~s}$ do exist. It has to be noted that Xing et al. (2018) considered Zhoukoudian $H$. erectus specimen PA 67 as three-rooted because of the presence of a small and unattached pulp diverticulum between the two main canals (Xing et al., 2018: Figure 2). However, because of its position in the inter-radicular blade and flatten shape, we consider this to represent a side-effect of the partial fusing of the two radicles and not a third root canal (see Supporting Information Table 1). If we enlarge our sample to other contemporaneous Zhoukoudian $H$. erectus materials (which were lost during WWII), Weidenreich (1937) described a few double-rooted premolars with incompletely separated root branches; in fact, $2 / 3$ of $\mathrm{P}^{3} \mathrm{~s}$ and $2 / 2$ of $\mathrm{P}^{4} \mathrm{~s}$ recorded by Weidenreich (1937) show this feature. Partly divided upper premolar roots are also 
frequently found in Neanderthals (this study) and is seen in one Middle Pleistocene $H$. floresiensis-like specimen (SOAMM5) from Mata Menge, Flores (van den Bergh et al., 2016). While the premolar root morphology of the early modern human assemblage from Jebel Irhoud, in Morocco, is still unreported (Hublin et al., 2017), the recently published late Middle Pleistocene modern human maxilla from Misliya, in Israel, showed singlerooted upper premolars (Hershkovitz et al., 2018). Double-rooted lower premolars are frequently reported for Early Pleistocene hominins found in Eurasian sites like Atapureca TD6 (Bermúdez de Castro \& Rosas, 1999) and Sangiran (Kaifu et al., 2005), but East African early Homo has predominantly single- or Tomes' rooted lower premolars (Wood et al., 1988), high percentage of Tomes' root is also observed in Early Pleistocene specimens from Atapuerca TD6 and Sima del Elefante (Prado-Simón et al. 2012, b), Dmanisi and Trinil (Martinón-Torres et al., 2008). As for the Middle Pleistocene period, Tomes' root has been described for the specimens found in Tighenif (accompanied with two or three canals; Zanolli \& Mazurier, 2013), mid-Middle Pleistocene specimens like $H$. erectus $\mathrm{P}_{4}$ from Hexian (Liu et al., 2017) and Zhoukoudian (3/5 $\mathrm{P}_{3 \mathrm{~S}}$ and 1/2 $\mathrm{P}_{4 \mathrm{~s}}$; Weidenreich, 1937), $\mathrm{P}_{3}$ from Chenjiawo (this study) and a late Middle Pleistocene P3 of Penghu 1 (Chang et al., 2015). A three-grooved $\mathrm{P}_{4}$ root (with one circular canal) is seen in late Middle Pleistocene specimen from Changyang (this study), representing a fusion of three root branches-a rather primitive feature. In all, our Middle Pleistocene record from China fits this evolutionary scenario, with a retention of primitive and derived features associated with root and canal simplification. Single-rooted lower premolars are also frequently reported for the Middle Pleistocene hominins from Eurasia, including specimens from Zhoukoudian (Weidenreich, 1937; Xing et al., 2018; Zanolli, Pan, et al., 2018) and Chenjiawo (this study), the $\mathrm{P}_{4}$ of Penghu 1 (Chang et al., 2015), Qesem Cave (Hershkovitz et al., 2011), Atapuerca Sima de los Huesos (Martinón-Torres et al., 2012), and Visogliano (Zanolli et al., 2018). In the Late Pleistocene, Neanderthal premolars shows more homogeneity in their rootcanal form. All the $\mathrm{P}_{3}$ s have double roots and all the $\mathrm{P}_{3}$ s have single root. Moreover, all the Neanderthal P4s show single root (1R) with one or two canals except for one specimen (KRD 35) that exhibits Tomes' root with deep MB groove and two MB + DL canals (Supporting Information Table 1). These results based on a larger sample are comparable to those from Prado-Simón, Martinón- Torres, Baca, Olejniczak, et al. (2012). However, the majority of our Neanderthal sample comes from Krapina and further investigation is needed to test whether this low variability on the premolar rootcanal form exists in other Neanderthal populations. The modern human lower premolars show derived root forms of predominantly, if not all, single root with one canal. Despite the tendency towards a simplification of the root system across the Middle Pleistocene in Eurasian human groups, the ancestral pattern is found to be retained in multiple human groups through time and space, probably indicating the survival of primitive lineages, but more evidence is needed to make any phylogenetic interpretations. In all, premolar root and canal form of midMiddle Pleistocene hominins inhabiting China (or "classic" H. erectus) show closer affinities with their contemporaneous or older counterparts in Eurasia, than with East 
African early Homo. This evidence is consistent with the hypothesis that at least some of the Early Pleistocene hominins occupying Eurasia contributed to the later "classic" $H$. erectus population (Kaifu et al., 2005; Martinón-Torres et al., 2007, 2008). As for the late Middle Pleistocene specimens, although they are often assigned to archaic H. sapiens and display a series of derived features, we record here a number of primitive features that cannot be strictly aligned across a chronological sequence. Together with root-canal configurations reported here, current detal evidence cannot confidently link these Middle Pleistocene population to the $H$. sapiens lineage, although an evolutionary trend toward this condition is clearly observed (Bailey \& Liu, 2010; Liu et al., 2013).

\section{Conclusions}

Previous studies have reported a high degree of morphological complexity in tooth crown and enamel-dental junction (Liu et al., 2013, 2016, 2017; Xing et al., 2016; Xing, Zhou, \& Liu, 2009), compatible with our results on the root and pulp canal. Together with a clear trend of root number reduction during the Middle and Late Pleistocene, our study revealed a previously undocumented level of diversity in root-canal configuration within the hominins that occupied East Asia in Middle Pleistocene period. In all, premolar root and canal form we observed in "classic" H. erectus population is comparable to Early and Middle Pleistocene hominins in Eurasia, but show distant morphological affinities to East African early hominins. This work shows that analyzing the variation of premolar root structural organization, and notably integrating together root/canal form and number, could possibly contribute to taxonomic and phylogenetic discussions. Future investigations is needed, for example, by characterizing the root-canal morphology of the Indonesian EarlyMiddle Pleistocene hypodigm in order to better understand the still obscure evolutionary relationships and population dynamics with the Asian continental groups.

\section{Acknowledgements}

For access to comparative materials we are grateful to P. Bayle, G. Kruger, O. Kullmer, E. L'Abbé, D. S. Li, A. Oettlé, F. Schrenk, and R. Machiarelli. We also acknowledge the

Nespos Society (www. nespos.org). For the elaboration of micro-CT record of the 
comparative material we thank F. Bernardini, B. Duployer, Y. M. Hou, and C. Tenailleau.

We are also indebted to W. Liu and S. Xing for sharing micro-CT record of some Chinese fossil specimens, and also for scientific discussion and comments. Research supported by

Strategic Priority Research Program of Chinese Academy of Sciences (No. XDB26000000), State Key Laboratory of Palaeobiology and Stratigraphy (Nanjing

Institute of Geology and Palaeontology, CAS; No. 173119), National Natural Science Foundation of China (No. 41702026, No. 41872030).

\section{References}

Abbott SA. 1984. A comparative study of tooth root morphology in the great apes, modern man and early hominids: Ph. D. Dissertation, University of London.

An Z, Kun HC. 1989. New magnetostratigraphic dates of Lantian Homo erectus. Quaternary Research 32:213-221.

Bailey SE, Liu W. 2010. A comparative dental metrical and morphological analysis of a Middle Pleistocene hominin maxilla from Chaoxian (Chaohu), China. Quaternary International 211:14-23.

Bellizzi R, Hartwell G. 1985. Radiographic evaluation of root canal anatomy of in vivo endodontically treated maxillary premolars. Journal of Endodontics 11:37-39.

Bermúdez de Castro JM, Martinón-Torres M, Sier MJ, et al. 2014. On the variability of the Dmanisi mandibles. PLOS ONE 9:e88212.

Bermúdez de Castro JM, Rosas A. 1999. Dental remains from Atapuerca-TD6 (Gran Dolina site, Burgos, Spain). Journal of Human Evolution 37:523-566.

Brook A. 2009. Multilevel complex interactions between genetic, epigenetic and environmental factors in the aetiology of anomalies of dental development. Archives of Oral Biology 54:S3-S17.

Brown P, Maeda T. 2009. Liang Bua Homo floresiensis mandibles and mandibular teeth: a contribution to the comparative morphology of a new hominin species. Journal of Human Evolution 57:571-596.

Chang C-H, Kaifu Y, Takai M, et al. 2015. The first archaic Homo from Taiwan. Nature Communications 6:6037.

Chia L. 1957. Notes on the human and some other mammalian remains from Changyang, Hupei. Acta Anthropologica Sinica 1:179-190.

Grün R, Huang P-H, Huang W, et al. 1998. ESR and U-series analyses of teeth from the palaeoanthropological site of Hexian, Anhui Province, China. Journal of Human Evolution 34:555564.

Grün R, Huang P-H, Wu X, et al. 1997. ESR analysis of teeth from the palaeoanthropological site of Zhoukoudian, China. Journal of Human Evolution 32:83-91.

Han F, Sun C, Bahain J-J, et al. 2016. Coupled ESR and U-series dating of fossil teeth from Yiyuan hominin site, northern China. Quaternary International 400:195-201.

Harvati K, Panagopoulou E, Karkanas P. 2003. First Neanderthal remains from Greece: the evidence from 
Lakonis. Journal of Human Evolution 45:465-473.

Hershkovitz I, Weber GW, Quam R, et al. 2018. The earliest modern humans outside Africa. Science 359:456-459.

Hoffman JW, de Beer F. 2012. Characteristics of the micro-focus X-ray tomography facility (MIXRAD) at Necsa in South Africa. $18^{\text {th }}$ World Conference on Nondestructive Testing, Durban, South Africa.

Huang P-H, Jin S-Z, Peng Z-C, et al. 1993. ESR dating of tooth enamel: comparison with U-Series, FT and TL dating at the Peking Man Site. Applied Radiation and Isotopes 44:239-242.

Hublin J-J, Ben-Ncer A, Bailey SE, et al. 2018. New fossils from Jebel Irhoud, Morocco and the pan-African origin of Homo sapiens. Nature 546:289-292.

Huffman OF. 2001. Geologic context and age of the Perning/Mojokerto Homo erectus, East Java. Journal of Human Evolution 40:353-362.

Kaifu Y. 2017. Archaic hominin populations in Asia before the arrival of modern humans: their phylogeny and implications for the "Southern Denisovans". Current Anthropology 58.

Kaifu Y, Baba H, Aziz F, et al. 2005. Taxonomic affinities and evolutionary history of the Early Pleistocene hominids of Java: dentognathic evidence. American Journal of Physical Anthropology 128:709-726.

Kaifu Y, Kono RT, Sutikna T, et al. 2015. Unique dental morphology of Homo floresiensis and its evolutionary implications. PLOS ONE 10.

Kallay J. 1963. A radiographic study of the Neanderthal teeth from Krapina, Croatia. In: Brothwell D, editor. Dental Anthropology. New York: Pergamon Press. p 75-86.

Kottoor J, Albuquerque D, Velmurugan N, et al. 2013. Root anatomy and root canal configuration of human permanent mandibular premolars: a systematic review. Anatomy Research International 2013. Article ID 254250.

Kupczik K, Dean MC. 2008. Comparative observations on the tooth root morphology of Gigantopithecus blacki. Journal of Human Evolution 54:196-204.

Kupczik K, Hublin J-J. 2010. Mandibular molar root morphology in Neanderthals and Late Pleistocene and recent Homo sapiens. Journal of Human Evolution 59:525-541.

Kupczik K, Spoor F, Pommert A, et al. 2005. Premolar root number variation in hominoids: genetic polymorphism vs. functional significance. In: Żądzińska E, editor. Current Trends in Dental Morphology Research. Lodz: University of Lodz Press. p 257-268.

Liu W, Clarke R, Xing S. 2010. Geometric morphometric analysis of the early Pleistocene hominin teeth from Jianshi, Hubei Province, China. Science China Earth Sciences 53:1141-1152.

Liu W, Martinón-Torres M, Kaifu Y, et al. 2017. A mandible from the Middle Pleistocene Hexian site and its significance in relation to the variability of Asian Homo erectus. American Journal of Physical AnthropologyDOI: 10.1002/ajpa.23162.

Liu W, Schepartz LA, Xing S, et al. 2013. Late Middle Pleistocene hominin teeth from Panxian Dadong, South China. Journal of Human Evolution 64:337-355.

Liu W, Xing S, Wu X. 2016. Morphological diversities of the late-Middle and Late Pleistocene human fossils in China (in Chinese). SCIENTIA SINICA Terrae 46:906-917.

Loh H. 1998. Root morphology of the maxillary first premolar in Singaporeans. Australian Dental Journal 43:399-402.

Lü Z, Huang Y, Li P, et al. 1989. Yiyuan fossil man (In Chinese with English abstract). Acta Anthropologica 
Sinica 8:301-313.

Macchiarelli R, Bondioli L, Debénath A, et al. 2006. How Neanderthal molar teeth grew. Nature 444:748751.

Martinón-Torres M, Bermúdez de Castro JM, Gómez-Robles A, et al. 2008. Dental remains from Dmanisi (Republic of Georgia): morphological analysis and comparative study. Journal of Human Evolution 55:249-273.

Moggi-Cecchi J, Menter C, Boccone S, et al. 2010. Early hominin dental remains from the Plio-Pleistocene site of Drimolen, South Africa. Journal of Human Evolution 58:374-405.

Moore NC, Hublin JJ, Skinner MM. 2015. Premolar root and canal variation in extant non-human hominoidea. American Journal of Physical Anthropology 158:209-226.

Moore NC, Skinner MM, Hublin JJ. 2013. Premolar root morphology and metric variation in Pan troglodytes verus. American Journal of Physical Anthropology 150:632-646.

Moore NC, Thackeray JF, Hublin J-J, et al. 2016. Premolar root and canal variation in South African PlioPleistocene specimens attributed to Australopithecus africanus and Paranthropus robustus. Journal of Human Evolution 93:46-62.

NESPOS database. 2017. NEanderthal Studies Professional Online Service. http://www.nespos.org.

Pan L, Thackeray JF, Dumoncel J, et al. 2017. Intra-individual metameric variation expressed at the enameldentine junction of lower post-canine dentition of South African fossil hominins and modern humans. American Journal of Physical Anthropology 163:806-815.

Peiris R. 2008. Root and canal morphology of human permanent teeth in a Sri Lankan and Japanese population. Anthropological Science 116:123-133.

Prado-Simón L, Martinón-Torres M, Baca P, et al. 2012a. A morphological study of the tooth roots of the Sima del Elefante mandible (Atapuerca, Spain): a new classification of the teeth-biological and methodological considerations. Anthropological Science 120:61-72.

Prado-Simón L, Martinón-Torres M, Baca P, et al. 2012b. Three-dimensional evaluation of root canal morphology in lower second premolars of early and middle pleistocene human populations from atapuerca (Burgos, Spain). American Journal of Physical Anthropology 147:452-461.

Rink WJ, Schwarcz HP, Smith FH, et al. 1995. ESR dates for Krapina hominids. Nature 378:24.

Robinson JT. 1956. The dentition of the Australopithecinae. Transvaal Museum Memoir No 9:1-179.

Schepartz LA, Miller-Antonio S. 2004. Asia and the middle pleistocene in global perspective. Asian Perspectives 43:187-190.

Sert S, Bayirli GS. 2004. Evaluation of the root canal configurations of the mandibular and maxillary permanent teeth by gender in the Turkish population. Journal of Endodontics 30:391-398.

Shaw JCM. 1931. The teeth, the bony palate and the mandible in Bantu races of South Africa. London: John Bale, Sons \& Danielson.

Shen G, Fang Y, Bischoff JL, et al. 2010. Mass spectrometric U-series dating of the Chaoxian hominin site at Yinshan, eastern China. Quaternary International 211:24-28.

Shen G, Ku T-L, Cheng H, et al. 2001. High-precision U-series dating of Locality 1 at Zhoukoudian, China. Journal of Human Evolution 41:679-688.

Shields ED. 2005. Mandibular premolar and second molar root morphological variation in modern humans: what root number can tell us about tooth morphogenesis. American Journal of Physical 
Anthropology 128:299-311.

Sikri VK, Sikri P. 1994. Mandibular premolars: aberrations in pulp space morphology. Indian journal of dental research 5:9-14.

Spencer MA. 2003. Tooth-root form and function in platyrrhine seed-eaters. American Journal of Physical Anthropology 122:325-335.

Sperber GH. 1974. Morphology of the cheek teeth of early South African hominids: Ph. D. Dissertation, University of the Witwatersrand.

Tobias P. 1995. Root number in the maxillary third premolars: a very ancient polymorphism. In: MoggiCecchi J, editor. Aspects of Dental Biology: Palaeontology, Anthropology and Evolution. Florence: International Institute for the Study of Man. p 283-290.

Tomes CS. 1923. A manual of dental anatomy: human and comparative. 8th ed. New York: MacMillan Co.

Tuniz C, Bernardini F, Cicuttin A, et al. 2013. The ICTP-Elettra X-ray laboratory for cultural heritage and archaeology. A facility for training and education in the developing world. Nucl Instrum Meth 711:106-110.

Turner CG. 1981. Root number determination in maxillary first premolars for modern human populations. American Journal of Physical Anthropology 54:59-62.

Turner CG, Nichol CR, Scott GR. 1991. Scoring procedures for key morphological traits of the permanent dentition: the Arizona State University dental anthropology system. In: Kelley MA, and Larsen CS, editors. Advances in Dental Anthropology. New York: Wiley-Liss. p 31-31.

van den Bergh GD, Kaifu Y, Kurniawan I, et al. 2016. Homo floresiensis-like fossils from the early Middle Pleistocene of Flores. Nature 534:245-248.

von Koenigswald GHR. 1950. Fossil hominids from the Lower Pleistocene of Java. Rep18th Internat Geol Congr 1948. London. p 59-61.

von Koenigswald GHR, Weidenreich F. 1939. The relationship between Pithecanthropus and Sinanthropus.

Weidenreich F. 1937. The dentition of Sinanthropus pekinensis: a comparative odontography of the hominids. Palaeontol Sin Series D I:1-180.

White TD, Suwa G, Simpson S, et al. 2000. Jaws and teeth of Australopithecus afarensis from Maka, Middle Awash, Ethiopia. American Journal of Physical Anthropology 111:45-68.

Woo J-k. 1964. Mandible of Sinanthropus lantianensis. Current Anthropology 5:98-101.

Woo J-k. 1966. The skull of Lantian man. Current Anthropology 7:83-86.

Wood B, Abbott S, Uytterschaut H. 1988. Analysis of the dental morphology of Plio-Pleistocene hominids. IV. Mandibular postcanine root morphology. Journal of Anatomy 156:107-139.

Wood B, Engleman C. 1988. Analysis of the dental morphology of Plio-Pleistocene hominids. V. Maxillary postcanine tooth morphology. Journal of Anatomy 161:1-35.

Wu X, Wu R. 1982. Human fossil teeth from Xichuan, Henan (In Chinese with English abstract). Vertabrata Palasiatica 20:1-10.

Xing S. 2012. Morphological variation of Zhoukoudian H. erectus teeth: Ph.D. Dissertation, Graduate University of Chinese Academy of Sciences.

Xing S, Martinón-Torres M, Bermúdez de Castro JM. 2018. The fossil teeth of the Peking Man. Scientific Report 8:2066.

Xing S, Martinón-Torres M, de Castro JMB, et al. 2014. Middle Pleistocene hominin teeth from Longtan 
Cave, Hexian, China. PLOS ONE 9:e114265.

Xing S, Sun C, Martinón-Torres M, et al. 2016. Hominin teeth from the Middle Pleistocene site of Yiyuan, Eastern China. Journal of Human Evolution 95:33-54.

Xing S, Zhou M, Liu W. 2009. Crown morphology and variation of the lower premolars of Zhoukoudian Homo erectus. Chinese Science Bulletin 54:3905-3915.

Yuan S, Chen T, Gao S. 1986. Uranium series chronological sequence of some palaeolithic sites in South China (In Chinese with English abstract). Acta Anthropologica Sinica 2:179-190.

Zanolli C, Martinón-Torres M, Bernardini F, et al. 2018. The Middle Pleistocene (MIS 12) human dental remains from Fontana Ranuccio (Latium) and Visogliano (Friuli-Venezia Giulia), Italy. A comparative high resolution endostructural assessment. PLOS ONE (in press).

Zanolli C, Mazurier A. 2013. Endostructural characterization of the H. heidelbergensis dental remains from the early Middle Pleistocene site of Tighenif, Algeria. Comptes Rendus Palevol 12:293-304.

Zanolli C, Pan L, Dumoncel J, et al. 2018a. Inner tooth morphology of Homo erectus from Zhoukoudian. New evidence from an old collection housed at Uppsala University, Sweden. Journal of Human Evolution 116:1-13.

Zdansky O. 1952. A new tooth of Sinanthropus pekinensis Black. Acta Zool 33:189-191.

Zhu ZY, Dennell R, Huang WW, et al. 2015. New dating of the Homo erectus cranium from Lantian (Gongwangling), China. Journal of Human Evolution 78:144-157. 